Proceedings

\title{
Reduced Graphene Oxide on Screen-Printed Carbon Electrodes as Biosensor for Escherichia coli O157:H7 Detection $^{+}$
}

\author{
Piravin Raj Barthasarathy 1,2, Nasteho Ali Ahmed 1, Wan Wardatul Amani Wan Salim 1,* \\ 1 Department of Biotechnology Engineering, Faculty of Engineering, International Islamic University \\ Malaysia, Gombak 50728, Kuala Lumpur, Malaysia; rajpiravin@gmail.com (P.R.B); \\ naswoo23@gmail.com (N.A.A.) \\ 2 nanoSkunkWorkX Sdn. Bhd., Level 11, Menara KEN TTDI, 37 Jalan Burhanuddin Helmi, Taman Tun Dr. \\ Ismail 60000, Kuala Lumpur, Malaysia \\ * Correspondence: asalim@iium.edu.my; Tel.: +603-6421-5432 \\ + Presented at the 1st International Electronic Conference on Biosensors, 2-17 November 2020; Available \\ online: https://iecb2020.sciforum.net/.
}

Received: date; Accepted: date; Published: date

\begin{abstract}
Mixture of drinking-water supplies with sewage discharges poses disease threats in floodstricken areas. In such exigent conditions, on-site testing of water samples is the only option, as water samples cannot be transported to laboratories owing to severely impacted transportation services. Hence, we developed a low-cost electrochemical biosensor fabricated from a screenprinted carbon electrode (SPCE) to detect $E$. coli $\mathrm{O} 157: \mathrm{H7}$, a virulent pathogen often found in sewage discharges. We focused on understanding antigen-antibody interaction when the antibody used is not specific for E. coli O157:H7. We found that antibody immobilized on a reduced graphene oxide (rGO)-modified SPCEs distinguished between E. coli O157:H7 concentrations of $4 \times 10^{8}$ and 4 $\mathrm{CFU} / \mathrm{mL}$, with lowest current reported for $4 \times 10^{8} \mathrm{CFU} / \mathrm{mL}$. In contrast, a reduced graphene oxidemodified SPCEs without antibody immobilization does not produce a prominent peak that distinguishes the highest and lowest E. coli concentrations. However, a few E. coli cells were still attached to the rGO/SPCEs in the absence of antibody, as shown in FESEM images. A processing step of differential readings from reference and active electrodes needs to be programmed into an Arduino ${ }^{\circledR}$ microprocessor to realize a prototype of a bacteria sensor for field use.
\end{abstract}

Keywords: screen-printed carbon electrode; E. coli O157:H7; reduced graphene oxide; electrochemical biosensor; water quality monitoring

\section{Introduction}

Rapid development and deployment of electrochemical biosensors for pathogen quantification is needed for use in flood-stricken areas where drinking-water supplies and sanitation systems are disrupted and making possible serious waterborne diseases. These outbreaks of waterborne diseases become more serious when flooding occurs in rural areas with limited resources, such the case of Kuala Krai, Kelantan, East Coast of Malaysia [1]. In the resource-constrained setting of Kuala Krai, water samples are filtered through microfiltration techniques that remove only large debris and are ineffective for removing bacteria and viruses [2,3]. However, water samples generally cannot be sent to laboratories for biochemical analysis owing to severely impacted transportation facilities. Hence, on-site testing using biosensors may be the only option in such emergency situations. Biosensors for pathogen quantification can be developed by following WHO ASSURED - affordable, sensitive, specific, user-friendly, rapid and robust, equipment-free, and deliverable to end-users - guidelines 
for diagnostic devices for use in resource-constrained settings [4]. In this paper, we describe a lowcost electrochemical biosensor that can be integrated into an Arduino ${ }^{\circledR}$ microprocessor encased in a portable platform for Escherichia coli (E. coli) O157:H7 detection. To fulfil ASSURED criteria, antibodies used in the biosensors require a very specific epitope to the $E$. coli strain because surface proteins with similar homologs across bacterial species can lead to non-specific binding [5]. We aim to understand the effect of E. coli O157:H7 binding to an antibody (Immunoglobulin G, IgG) not specific for $E$. coli O157:H7 on the measurements made by electrochemical biosensors fabricated from screen-printed carbon electrodes (SPCEs), and their suitability for use in flood-stricken areas.

\section{Materials and Methods}

\subsection{Chemicals and Reagents}

Ultra-highly concentrated single-layer graphene oxide (UHC GO, $6.2 \mathrm{mg} / \mathrm{mL}$ ) was purchased from Graphene Supermarket, Richmond, NY, USA. Potassium ferricyanide $\left(\mathrm{K}_{3} \mathrm{Fe}(\mathrm{CN})_{6}\right)$, potassium ferrocyanide $\left(\mathrm{K}_{4} \mathrm{Fe}(\mathrm{CN}) 6 \cdot 3 \mathrm{H}_{2} \mathrm{O}\right)$, phosphate buffered saline (PBS, pH 7.4) tablets, sulfuric acid $\left(\mathrm{H}_{2} \mathrm{SO}_{4}\right)$, hydrochloric acid $(\mathrm{HCl}), \mathrm{N}$-hydroxysulfosuccinimide (NHS), 1-ethyl-3-(3-dimethylaminopropyl) carbodiimide (EDC), and IgG from rabbit serum (I5006) were purchased from Sigma-Aldrich, St. Louis, MI, USA. PBS tablets were dissolved in deionized water, and the $\mathrm{pH}$ was adjusted by addition of hydrochloric acid ( $\mathrm{HCl})$. Heat-killed Escherichia coli serotype O157:H7 in dextran solution (Product ID: 50-95-90) was purchased from Kirkegaard and Perry Lab (KPL) Inc., Gaithersburg, Maryland, United States. Tap water was collected from sink taps at the Kinetics Laboratory (Faculty of Engineering, IIUM, Malaysia). Deionized water was used throughout this study unless stated otherwise.

\subsection{Instrumentation}

SPCE activation, graphene oxide reduction, and electrochemical measurements were performed using a portable pocketSTAT (IVIUM Technologies, Eindhoven, The Netherlands) at ambient temperature. The results were analysed using IviumSoft software. Screen-printed carbon electrodes (SPCEs) with $\varnothing=2 \mathrm{~mm}$-diameter working electrodes (WE) were purchased from Pine Instrument, Grove City, Pennsylvania, United States. The reference electrode (RE) is $\mathrm{Ag} / \mathrm{AgCl}$, and the counter electrode (CE) is made of carbon. Morphological change in the modified SPCEs incubated with different E. coli concentrations was observed via field emission scanning electron microscopy (FESEM) using a Hitachi SU8020 UHR Cold-Emission FESEM available at MIMOS Technology Solutions, Sdn. Bhd., Seri Kembangan, Selangor, Malaysia.

\subsection{Preparation of $G O, r G O$, and $I g G / r G O$ Electrodes}

All SPCEs were activated using repetitive cyclic voltammetry for 3 cycles at a scanning potential of 2.5 to $-2.5 \mathrm{~V}$, and scan rate of $100 \mathrm{mV} / \mathrm{s}$ in $0.1 \mathrm{M} \mathrm{H}_{2} \mathrm{SO}_{4}$. GO/SPCEs were prepared by drop-casting $3 \mu \mathrm{l} \mathrm{GO}$ onto the WE of an activated SPCE, and dried at ambient temperature for $2 \mathrm{~h}$. To prepare rGO/SPCEs, GO/SPCEs were electrochemically reduced using repetitive $\mathrm{CV}$ for 5 cycles at a scanning potential of 0 to $-1.5 \mathrm{~V}$, and scan rate of $100 \mathrm{mV} / \mathrm{s}$ in PBS, $\mathrm{pH}$ 5.0. Then, $3 \mu \mathrm{L}$ 1-ethyl-3-(3dimethylaminopropyl) carbodiimide (EDC; $0.5 \mathrm{M}$ ) and N-hydroxysulfosuccinimide (NHS; $0.1 \mathrm{M}$ ) (ratio: 1:1) composite was drop-cast onto the WE of an $\mathrm{rGO} / \mathrm{SPCE}$, and dried at $37^{\circ} \mathrm{C}$ for $20 \mathrm{~min}$. Three (3) $\mu \mathrm{L} \operatorname{IgG}(2 \mu \mathrm{g} / \mathrm{mL})$ was drop-cast onto the WE of an rGO/SPCE with EDC-NHS, and incubated at $37^{\circ} \mathrm{C}$ for $2 \mathrm{~h}$. The electrode was rinsed with PBS, pH 7.1, to remove unbound IgG. All modified electrodes were stored in a $90 \times 15-\mathrm{mm}$ (diameter $\times$ height) Petri dish and kept at ambient temperature until needed for further use.

\subsection{Characterization}

\subsubsection{Linear Sweep Voltammetry (LSV) Measurements}


LSV was performed at a scanning potential of -0.5 to $1 \mathrm{~V}$, and scan rates of 25, 50, 100, 125, 150, and $200 \mathrm{mV} / \mathrm{s}$ in $0.01 \mathrm{M}$ PBS, pH 7.1, containing $5 \mathrm{mM} \mathrm{K} \mathrm{K}_{3} \mathrm{Fe}(\mathrm{CN})_{6}: \mathrm{K}_{4} \mathrm{Fe}(\mathrm{CN})_{6}$ to determine the current flow in SPCEs, GO/SPCEs, rGO/SPCEs, and IgG/rGO/SPCEs. The half reaction that occurs at the electrode can be described by Equation (1) [6]:

$$
\mathrm{Fe}(\mathrm{CN})_{6}^{-3}+e^{-} \leftrightarrow \mathrm{Fe}(\mathrm{CN})_{6}^{-4}
$$

From the peak current obtained from LSV measurement, the graph of peak current (Ip) vs. square root of scan rate $\left(v^{1 / 2}\right)$ was plotted, and effective surface area was calculated from only the slopes of linear curves using the Randles Sevcik Equations (2) and (3) $[7,8]$ :

$$
\begin{gathered}
I p=\left(2.69 \times 10^{5}\right) n^{3 / 2} D^{1 / 2} C A v^{1 / 2} \\
A=k /\left(\left(2.69 \times 10^{5}\right) n^{\frac{3}{2}} D^{\frac{1}{2}} C\right),
\end{gathered}
$$

where the diffusion coefficient $\mathrm{D}$ for the ferricyanide/ferrocyanide redox couple is typically $6.70 \times$ $10^{-6} \mathrm{~cm}^{2} / \mathrm{s}$, C is the molar concentration of ferricyanide-ferrocyanide solution $(5 \mathrm{mM}), A$ is the effective surface area $\left(\mathrm{cm}^{2}\right), v$ is the scan rate $(\mathrm{mV} / \mathrm{s})$, and $n$ is the number of moles of electrons transferred per mole of electroactive species, which in this case is one (1).

The non-specific binding of E. coli O157:H7 to $\mathrm{rGO} / \mathrm{SPCEs}$ and IgG/rGO/SPCEs was tested using LSV. To prepare E. coli solution $\left(4 \times 10^{8}, 4 \times 10^{7}, 4 \times 10^{6}, 4 \times 10^{5}, 4 \times 10^{4}, 4 \times 10^{3}, 4 \times 10^{2}, 4 \times 10^{1}\right.$, and 4 $\mathrm{CFU} / \mathrm{mL})$, the stock solution $\left(3.98 \times 10^{9} \mathrm{CFU} / \mathrm{mL}\right.$ in dextran solution) was diluted with PBS, $\mathrm{pH} 7.1$. Then, $3 \mu \mathrm{l}$ diluted E. coli solution was drop-cast onto the WEs of IgG/rGO/SPCEs and rGO/SPCEs, and incubated at $37^{\circ} \mathrm{C}$ for $1 \mathrm{~h}$. Both SPCEs were washed with PBS, pH 7.1, to remove unbound $E$. coli. For SPCEs incubated with E. coli, LSV was performed at a scanning potential of -0.5 to $1 \mathrm{~V}$, and a scan rate of $100 \mathrm{mV} / \mathrm{s}$ in tap water.

\subsubsection{Field Emission Scanning Electron Microscopy}

The morphology of SPCEs incubated with E. coli was observed using a FESEM. The SPCEs were coated with platinum to avoid charging effects during FESEM imaging. FESEM images were obtained at a magnification of $5 \mathrm{~K}$ at all four quadrants of the WE to provide an overall overage of sensing area.

\section{Results and Discussion}

\subsection{Linear Sweep Voltammetry for Bare SPCEs, GO/SPCEs, $r G O / S P C E s$, and IgG/rGO/SPCEs}

Figure 1 shows LSV measurements of bare SPCEs, GO/SPCEs, rGO/SPCEs, and IgG/rGO/SPCEs conducted at a scanning potential of -0.5 to $1 \mathrm{~V}$ and scan rates of $25,50,100,125,150$, and $200 \mathrm{mV} / \mathrm{s}$ in $0.01 \mathrm{M}$ PBS, pH 7.1, containing $5 \mathrm{mM} \mathrm{K} \mathrm{K}_{3} \mathrm{Fe}(\mathrm{CN})_{6}: \mathrm{K}_{4} \mathrm{Fe}(\mathrm{CN})_{6}$. We compared the current values obtained at $100 \mathrm{mV} / \mathrm{s}$ to understand electron-transfer behavior on the bare SPCEs, GO/SPCEs, $\mathrm{rGO} / \mathrm{SPCEs}$, and IgG/rGO/SPCEs. At $0.7 \mathrm{~V}$, the bare SPCEs recorded higher current value of $14 \mu \mathrm{A}$ compared to the GO/SPCEs $(11 \mu \mathrm{A})$, because of the oxygenated functional groups that impair electron flow at the edges of GO $[9,10]$. The current value was improved to $23 \mu \mathrm{A}$ for $\mathrm{rGO} / \mathrm{SPCEs}$ owing to the electrochemical reduction process that removed a considerable number of oxygenated functional groups. Studies have shown that electrochemical reduction with precise control over the reduction potential and time $[11,12]$ allows reproducibility of rGO for use in electrochemical devices [13]. We found that IgG/rGO/SPCEs achieved the highest current value of $73 \mu \mathrm{A}$, which could be due to the semiconductive nature of protein in dry and wet states [14]. In addition, the conductivity can be influenced by the way in which IgG is immobilized on the electrode surface such that the alpha domain is more conductive than the beta domain of a protein [15].

Nanomaterials increase the effective surface area (Aeff); higher Aeff leads to improved sensitivity of biosensors. We plotted a graph of current (Ip) vs. square root of scan rate $\left(v^{1 / 2}\right)$ to determine Aeff. The Aeff of bare SPCEs and GO/SPCEs were $21.7 \mathrm{~mm}^{2}$ and $4.06 \times 10^{-9} \mathrm{~mm}^{2}$; the graphs of current (Ip) vs. square root of scan rate $\left(v^{1 / 2}\right)$ were linear. However, the graphs of current (Ip) vs. square root of 
scan rate $\left(v^{1 / 2}\right)$ for $\mathrm{rGO} / \mathrm{SPCEs}$ and $\mathrm{IgG} / \mathrm{rGO} / \mathrm{SPCEs}$ were non-linear, and hence we did not calculate Aeff. This non-linearity can be the result of a heterogenous electron-transfer process [16].

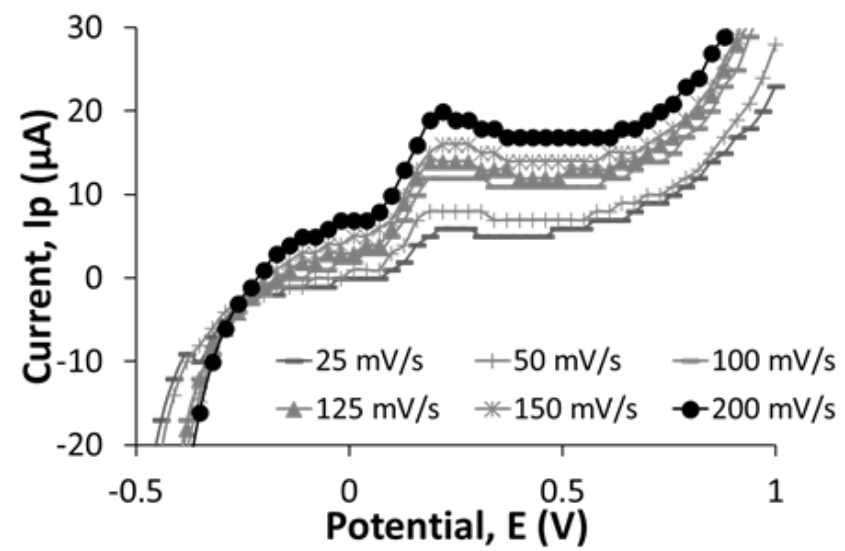

(a)

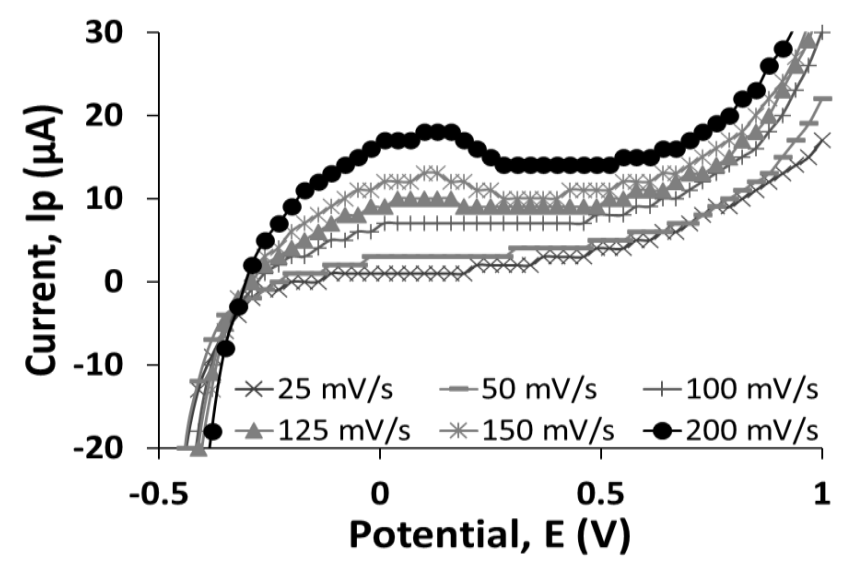

(b)

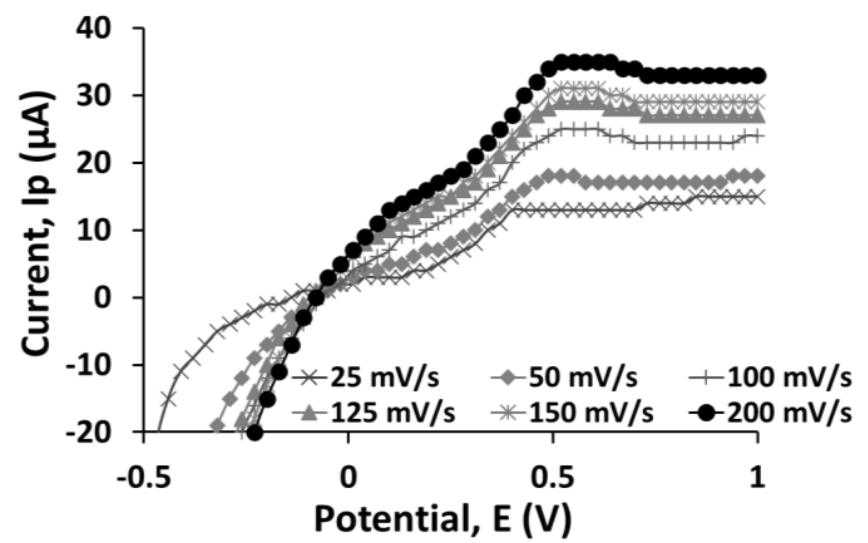

(c)
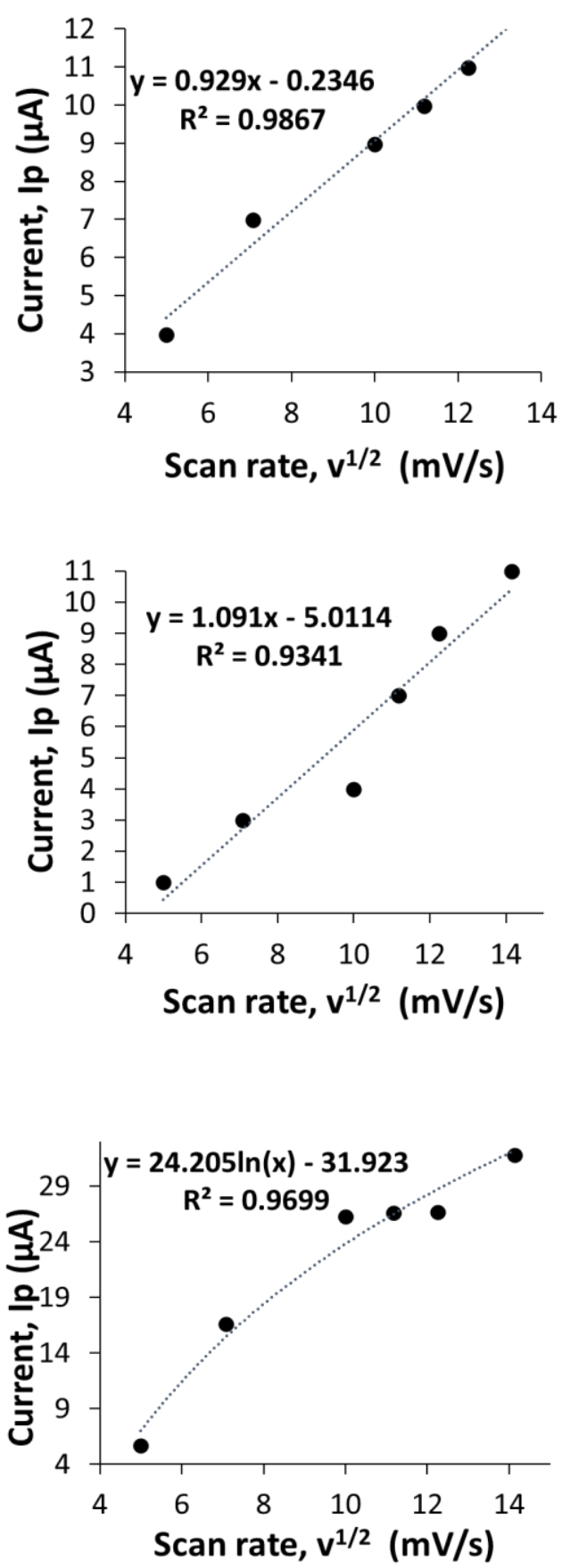


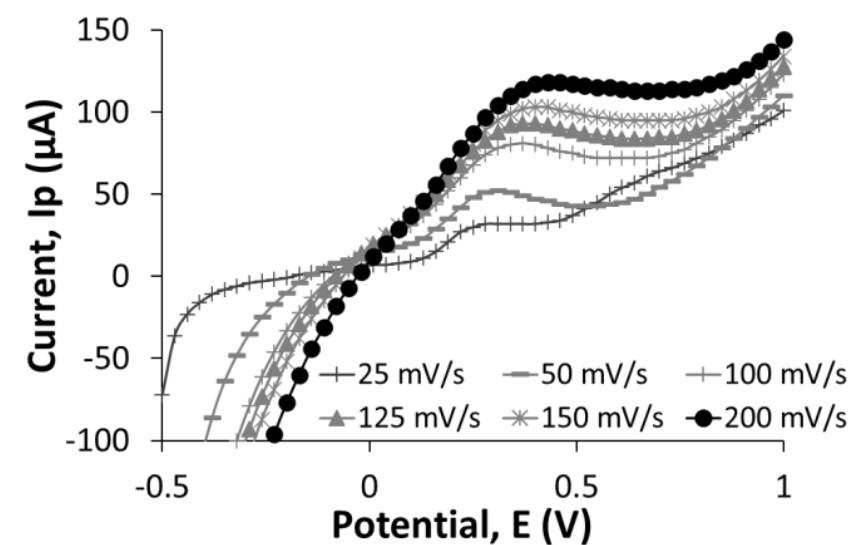

(d)

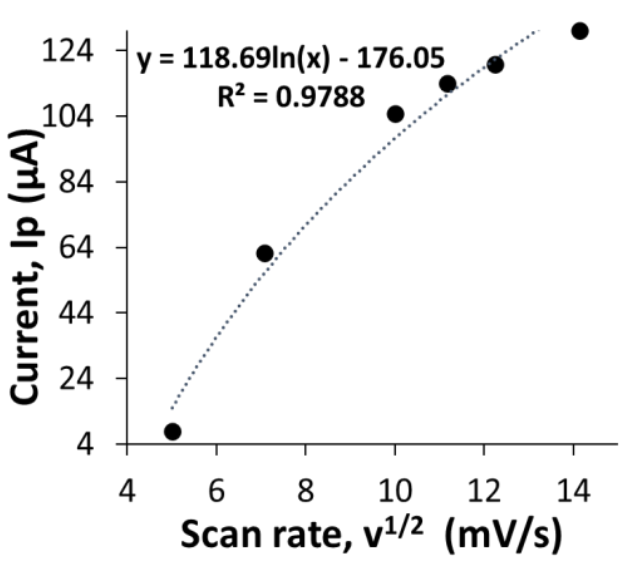

Figure 1. Linear sweep voltammetry (LSV) results of bare SPCEs (a), GO/SPCEs (b), rGO/SPCEs (c), and $\mathrm{IgG} / \mathrm{rGO} / \mathrm{SPCEs}(\mathrm{d})$ at different scan rate of 25, 50, 100, 125, 150, and $200 \mathrm{mV} / \mathrm{s}$ in ferricyanideferrocyanide solution. The figure indicates the electron-transfer behavior at the electrode surface as the potential sweep was run at -0.5 to $1 \mathrm{~V}$. The calibration curve of current (Ip, $\mu \mathrm{A})$ is plotted against square root of the scan rate $\left(v^{1 / 2}, \mathrm{mV} / \mathrm{s}\right)$ to observe the correlation between the current changes and the square root of scan rate.

\subsection{LSVs at Different E. coli Concentrations}

Figure 2 shows LSVs over a potential range of -0.5 to $1 \mathrm{~V}$ and scan rate of $100 \mathrm{mV} / \mathrm{s}$ for $\mathrm{IgG} / \mathrm{rGO} / \mathrm{SPCEs}$ and $\mathrm{rGO} / \mathrm{SPCEs}$ incubated with $E$. coli concentrations that ranged from $4 \times 10^{8}$ to 4 $\mathrm{CFU} / \mathrm{mL}$. We compared the current values obtained for the above-mentioned SPCEs; high current value indicates lower binding of $E$. coli cells to the IgG or the rGO surface. We performed preprocessing of the signal by subtracting the current value of zero E. coli from that of each E. coli concentrations.

In Figure 2a, a prominent peak was observed in the region of -0.35 to $0.07 \mathrm{~V}$, and the graphs for E. coli concentrations of $4 \times 10^{8}$ and $4 \mathrm{CFU} / \mathrm{mL}$ have a distinct gap in current values that enables us to differentiate between the highest and lowest concentrations. Incubation with a higher concentration of E. coli reported lower current value, implying a higher number of E. coli cells attached to $\mathrm{IgG} / \mathrm{rGO} / \mathrm{SPCEs}$. We found that current value does not increase linearly as the concentration of $E$. coli cells is reduced, which could be due to the random attachment of E. coli to IgG with low affinity for E. coli O157:H7. In addition to affinity, several IgGs could also potentially bind to a single bacterium, which might lead to random orientation of the E. coli cells on the surface of the electrode. IgG could bind to several outer membrane constituents of the E. coli, including its lipopolysaccharides and porins. Since the IgG used in this study is not specific to E. coli O157:H7, a condition of non-specific binding can be expected. However, we found that binding of $E$. coli to $\operatorname{IgG}$ occurred even at $E$. coli concentrations of $4 \mathrm{CFU} / \mathrm{mL}$. Therefore, a non-specific IgG can be used to detect but not quantify $E$. coli O157:H7 in the event of unavailability of antibody specific for E. coli O157:H7.

On the other hand, we found $\mathrm{rGO} / \mathrm{SPCEs}$ do not produce any distinctive peak between $E$. coli concentrations of $4 \times 10^{8}$ and $4 \mathrm{CFU} / \mathrm{mL}$ (Figure 2c). The LSV graphs overlapped for most of the $E$. coli concentration range, implying a random attachment of E. coli to the rGO surface. Studies have proven that rGO surfaces in general repel E. coli attachment [17], which could result in the random attachment of $E$. coli to the rGO surfaces. 


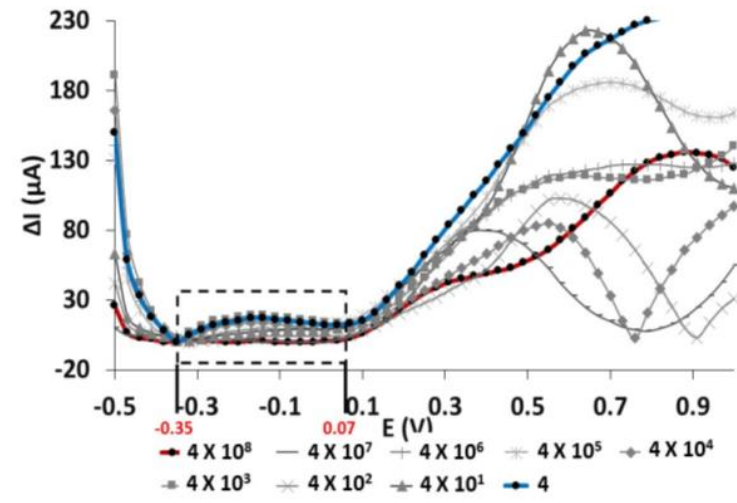

(a)

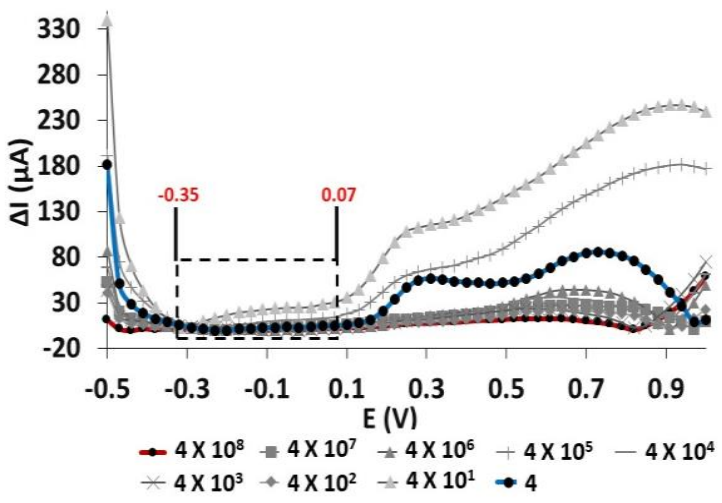

(c)

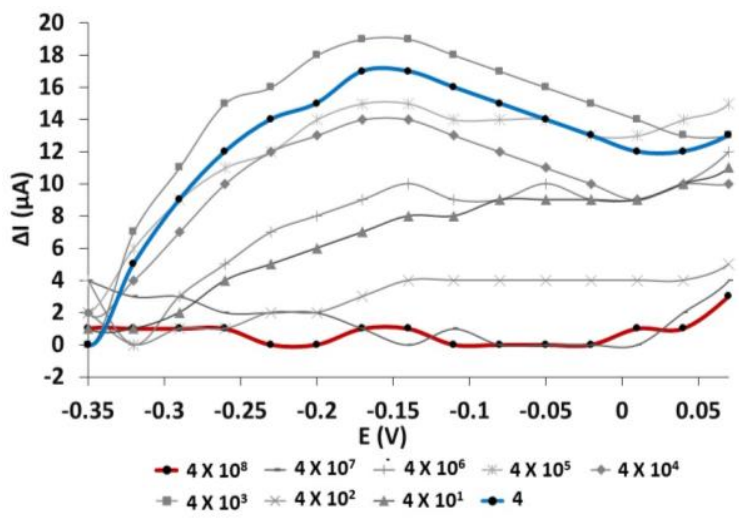

(b)

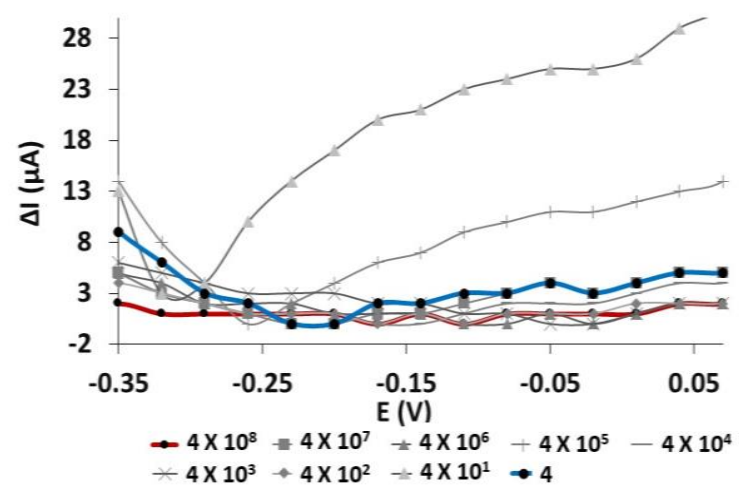

(d)

Figure 2. LSV graph of (a) IgG/rGO/SPCEs and (c) rGO/SPCEs treated with different concentrations of E. coli O157:H7 $\left(4 \times 10^{8}\right.$ to $\left.4 \mathrm{CFU} / \mathrm{mL}\right)$ in tap water at a scan rate of $100 \mathrm{mV} / \mathrm{s}$ and potential range of -0.5 to $1 \mathrm{~V}$. LSV graph of (b) $\mathrm{IgG} / \mathrm{rGO} / \mathrm{SPCEs}$ and (d) $\mathrm{rGO} / \mathrm{SPCEs}$ plotted at a potential range of -0.35 to $0.07 \mathrm{~V}$.

\subsection{Morphology of IgG/rGO/SPCEs and rGO/SPCES Incubated with E. coli O157:H7}

Figure 3 shows FESEM imaging of IgG/rGO/SPCEs incubated with (a) $4 \times 10^{7}$ and (b) $4 \times 10^{5}$ $\mathrm{CFU} / \mathrm{mL}$ E. coli. Higher amount of $E$. coli was attached to $\mathrm{IgG} / \mathrm{rGO} / \mathrm{SPCE}$ for $4 \times 10^{7} \mathrm{CFU} / \mathrm{mL}$ than for $4 \times 10^{5} \mathrm{CFU} / \mathrm{mL}$. The attachment of $E$. coli influences current value obtained during LSV; higher rate of attachment results in lower current value. We found that $\mathrm{IgG} / \mathrm{rGO} / \mathrm{SPCEs}$ incubated with $4 \times 10^{7}$ $\mathrm{CFU} / \mathrm{mL}$ reported lower current value than did those with $4 \times 10^{5} \mathrm{CFU} / \mathrm{mL}$, confirming that $E$. coli attachment blocks electron flow to the electrode surface. However, IgG/rGO/SPCEs incubated with 4 $\times 10^{3} \mathrm{CFU} / \mathrm{mL}$ reported higher current value than $4 \mathrm{CFU} / \mathrm{mL}$, implying E. coli attaches randomly to IgG and making the biosensor suitable only for E. coli O157:H7 detection and not quantification. We observed non-specific binding of E. coli O157:H7 to rGO/SPCEs (Figure 2 c). Studies have shown that E. coli O157:H7 attachment is dependent on orientation of the graphene structure; GO extracts phospholipids from the E. coli cell membrane onto the basal planes, which leads to bacterial cell death [18]. However, the basal plane of GO readily absorbs a variety of molecules via non-covalent interactions that quench the antibacterial property of GO [19]. In this study, we presume that molecules from the dextran solution (a medium used to store E. coli O157:H7) could possibly mask the basal plane, and thus E. coli are not destroyed when they adhere to rGO/SPCEs. 
(a)

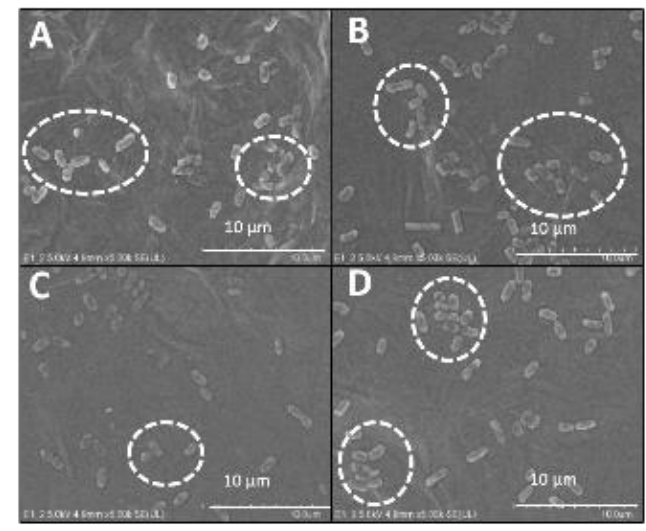

(c)

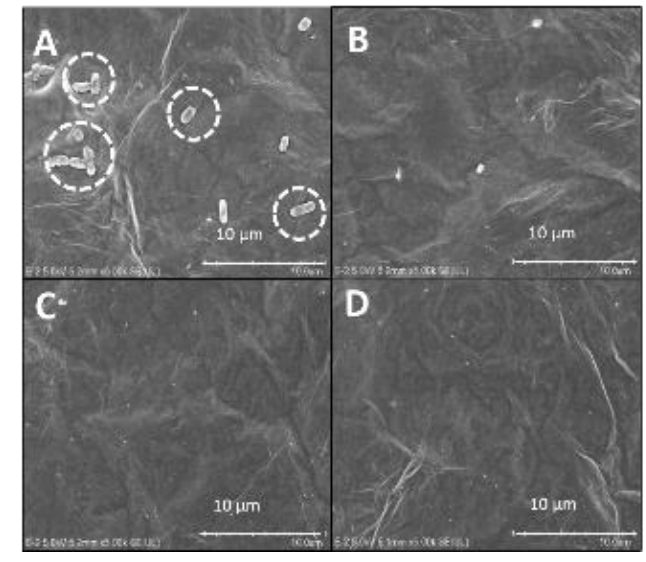

(b)

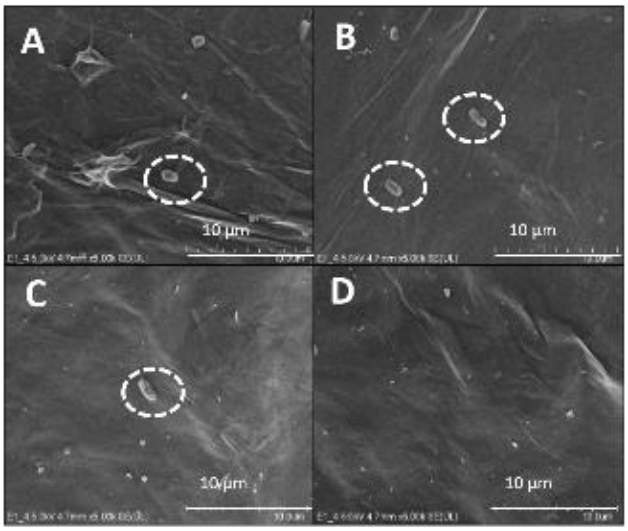

(d)

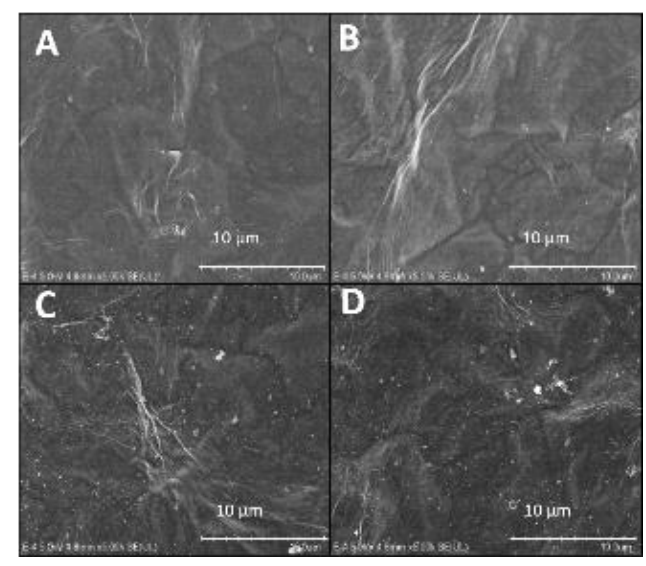

Figure 3. FESEM images showing cell attachment on electrode surfaces (shown with dotted lines). (a) and (b) $\mathrm{IgG} / \mathrm{rGO} / \mathrm{SPCEs}$ for $E$. coli concentrations of $4 \times 10^{7}$ and $4 \times 10^{5} \mathrm{CFU} / \mathrm{mL}$, respectively. (c) and (d) $\mathrm{rGO} / \mathrm{SPCEs}$ for E. coli concentrations of $4 \times 10^{7}$ and $4 \times 10^{5} \mathrm{CFU} / \mathrm{mL}$, respectively. FESEM images were taken for quadrants of $\varnothing=2 \mathrm{~mm}$-diameter WE of a SPCE.

\section{Conclusions}

We developed a low-cost electrochemical biosensor using antibody not specific towards E. coli O157:H7 immobilized on a screen-printed carbon electrode. The biosensor was able to distinguish between E. coli O157:H7 concentrations of $4 \times 10^{8}$ and $4 \mathrm{CFU} / \mathrm{mL}$, and hence allows the use of nonspecific IgG for E. coli O157:H7 detection but not quantification in the event of unavailability of antibody specific for E. coli O157:H7. Since E. coli O157:H7 attaches to rGO/SPCEs, an additional processing step is required wherein readings from reference electrode (without antibody) is subtracted from the working electrodes (with antibody). Such a processing step can be programmed in an Arduino ${ }^{\circledR}$ microprocessor and the biosensor can be made portable for use in flood-stricken areas.

Author Contributions: N.A.A. planned and performed the experiments, P.R. Barthasarathy drafted and wrote the manuscript, and validated the experimental results. W.W.A., W.S., the Principal Investigator, acquired funding for the work, provided the initial idea, contributed intellectually to the planning of the experimental design and validated the experimental results, edited and revised the manuscript content and writing, and approved the submitted version.

Funding: This research is funded by nanoSkunkWorkX Sdn. Bhd and the The Royal Society Travel Grant.

Acknowledgments: The authors would like to thank members of Amani Research Group for their assistance during preparation of electrodes.

Conflicts of Interest: The authors declare no conflict of interest. The funders had no role in the design of the study; in the collection, analysis, or interpretation of data; in the writing of the manuscript, or in the decision to 
publish the results. The preprints for this research is available for public viewing, and can be assessed at https://www.preprints.org/manuscript/201810.0631/v1.

\section{References}

1. Jaafar, A.S.; Sidek, L.M.; Basri, H.; Zahari, N.M.; Jajarmizadeh, M.; Noor, H.M.; Osman, S.; Mohammad, A.H.; Azad, W.H. An Overview: Flood Catastrophe of Kelantan Watershed in 2014; Springer Singapore: Singapore, 2016; pp. 17-29.

2. Madaeni, S.S. Microfiltration (MF). In Encyclopedia of Membranes; Drioli, E.; Giorno, L.; Eds.; Springer: Berlin, Heidelberg, 2015; pp. 1-3.

3. Zhu, B.; Clifford, D.A.; Chellam, S. Virus removal by iron coagulation-microfiltration. Water Res. 2005, 39, 5153-5161.

4. Kosack, C.S.; Page, A.-L.; Klatser, P.R. A guide to aid the selection of diagnostic tests. Bull. World Health Organ. 2017, 95, 639.

5. Byrne, B.; Stack, E.; Gilmartin, N.; O'Kennedy, R. Antibody-based sensors: Principles, problems and potential for detection of pathogens and associated toxins. Sensors 2009, 9, 4407-4445.

6. Huang, T.H.; Salter, G.; Kahn, S.L.; Gindt, Y.M. Redox titration of ferricyanide to ferrocyanide with ascorbic acid: Illustrating the Nernst equation and Beer-Lambert law. J. Chem. Educ. 2007, 84, 1461.

7. Bard, A.J.; Faulkner, L.R. Fundamentals and applications. Electrochem. Methods 2001, 2, 580-632.

8. Shi, J.; Claussen, J.C.; McLamore, E.S.; ul Haque, A.; Jaroch, D.; Diggs, A.R.; Calvo-Marzal, P.; Rickus, J.L.; Porterfield, D.M. A comparative study of enzyme immobilization strategies for multi-walled carbon nanotube glucose biosensors. Nanotechnology 2011, 22, 355502.

9. Pumera, M. Graphene in biosensing. Mater. Today 2011, 14, 308-315.

10. Azman, N.Z.M.; Zainal, P.N.S.; Alang Ahmad, S.A. Enhancement the electrochemical conductivity of a modified reduced graphene oxide/calixarene screen-printed electrode using response surface methodology. PLoS ONE 2020, 15, e0234148.

11. Gutić, S.J.; Kozlica, D.K.; Korać, F.; Bajuk-Bogdanović, D.; Mitrić, M.; Mirsky, V.M.; Mentus, S.V.; Pašti, I.A. Electrochemical tuning of capacitive response of graphene oxide. Phys. Chem. Chem. Phys. 2018, 20, 2269822709.

12. de Camargo, M.N.; Santhiago, M.; Maroneze, C.M.; Silva, C.C.; Timm, R.A.; Kubota, L.T. Tuning the electrochemical reduction of graphene oxide: Structural correlations towards the electrooxidation of nicotinamide adenine dinucleotide hydride. Electrochim. Acta 2016, 197, 194-199.

13. Ambrosi, A.; Pumera, M. Precise tuning of surface composition and electron-transfer properties of graphene oxide films through electroreduction. Chem. -A Eur. J. 2013, 19, 4748-4753.

14. Rosenberg, B. Electrical conductivity of proteins. Nature 1962, 193, 364-365.

15. Zhang, X.; Shao, J.; Jiang, S.; Wang, B.; Zheng, Y. Structure-dependent electrical conductivity of protein: Its differences between alpha-domain and beta-domain structures. Nanotechnology 2015, 26, 125702.

16. Chen, S.; Liu, Y.; Chen, J. Heterogeneous electron transfer at nanoscopic electrodes: Importance of electronic structures and electric double layers. Chem. Soc. Rev. 2014, 43, 372-5386.

17. Choudhary, P.; Das, S.K. Bio-reduced graphene oxide as a nanoscale antimicrobial coating for medical devices. ACS Omega 2019, 4, 387-397.

18. Tu, Y.; Lv, M.; Xiu, P.; Huynh, T.; Zhang, M.; Castelli, M.; Liu, Z.; Huang, Q.; Fan, C.; Fang, H. Destructive extraction of phospholipids from Escherichia coli membranes by graphene nanosheets. Nat. Nanotechnol. 2013, 8, 594.

19. Hui, L.; Piao, J.-G.; Auletta, J.; Hu, K.; Zhu, Y.; Meyer, T.; Liu, H.; Yang, L. Availability of the basal planes of graphene oxide determines whether it is antibacterial. ACS Appl. Mater. Interfaces 2014, 6, 13183-13190.

Publisher's Note: MDPI stays neutral with regard to jurisdictional claims in published maps and institutional affiliations.

(C) 2020 by the authors. Submitted for possible open access publication under the terms and conditions of the Creative Commons Attribution (CC BY) license (http://creativecommons.org/licenses/by/4.0/). 